project with a grant that enabled us to appoint Mrs B Killen, health visitor, whose dependable work led to successful patient follow-up and project quality control.

\section{References}

${ }^{1}$ Gardner, P S, et al, British Medical fournal, 1960, 1, 1077.

2 Howic, J G R, et al, Fournal of the Royal College of General Practitioners, $1971,21,657$.

${ }^{3}$ Howie, J G R, Fournal of the Royal College of General Practitioners, 1973, 23, 895.

+ Fry, J, The Catarrhal Child. London, Butterworth, 1966.

${ }^{5}$ British Thoracic Association Research Committee, British fournal of Diseases of the Chest $1972,66,199$.
${ }^{6}$ British Thoracic Association Research Committee, British fournal of Diseases of the Chest, 1973, 67, 114.

' Scott, K W M, British Fournal of Diseases of the Chest, 1973, 67, 43.

${ }^{8}$ British Medical fournal, 1974. 3, 1.

9 Andrews, C H, Science, 1964, 146, 1274.

1" Gordon, M, Lovell, S, and Dugdale, A E, Medical fournal of Australia, $1974,1,304$.

11 Howie, J G R, and Clark, G A, Lancet, 1970, 11, 1099.

12 Liss, R H, and Norman, J C, Chemotherapy 1975, 21. suppl No 1, p 27.

${ }^{13}$ Aitchison, W R C, Grant, I W B, and Gould, J C, British fournal of Clinical Practice, 1968, 22, 343.

${ }^{14}$ Agbim, O G, Current Medical Research Opinion, 1974, 2, 291.

${ }^{15}$ Pastel, M, Chemotherapy, 1975, 21, suppl No 1, p 91.

${ }^{16}$ Crombie, D, Lancet, 1963, 1, 1205.

17 Howie, J G R, Update, 1974, 1 September, p 539.

\title{
Hepatitis B virus infection in dental surgical practice
}

\author{
G F GOUBRAN， HELEN CULLENS，A J ZUCKERMAN， A L W F EDDLESTON， ROGER WILLIAMS
}

British Medical fournal, 1976, 2, 559-560

\section{Summary}

Sixty-one dental surgeons at King's College Hospital were interviewed to establish the incidence of attacks of viral hepatitis and to relate this to environmental risk factors. Six $\left(10^{\circ}\right)$ had a history of hepatitis, in one case due to infection with the hepatitis $B$ virus. Screening blood for HBsAg by radioimmunoassay showed no carriers of the antigen, but transient antigenaemia was observed in one dentist. Antibody to $\mathrm{HBs} \mathrm{Ag}$, tested by radioimmunoassay, was detected in four dentists $\left(7^{\circ}\right)$, only one of whom had had clinical hepatitis.

Dental surgeons may be more at risk from infection with the hepatitis $B$ virus than the general population, although this should be minimised in hospital practice, where the most infected patients will already have been identified and appropriate precautions can be taken. The risk of transmission from an antigen-positive dentist to his patients is probably much smaller, and there is no evidence to restrict his clinical activities.

\section{Introduction}

Several recent studies have suggested that both the attack rate for acute hepatitis B and the incidence of asymptomatic carriage of hepatitis $\mathrm{B}$ surface antigen $(\mathrm{HBs} \mathrm{Ag})$ are higher in dental surgeons than in the general population. ${ }^{12}$ Inevitably this has led to

\footnotetext{
Department of Oral and Maxillo-facial Surgery, King's College Hospital, London SE5

G F GOUBRAN, MB, FDS RCS, senior registrar (present address: Department of Oral and Maxillo-facial Surgery, Queen Victoria Hospital, East Grinstead, Sussex)

Liver unit, King's College Hospital, London SE5

HELEN CULLENS, ANZIMLT, senior technician

A L W F EDDLESTON, DM, MRCP, senior lecturer and consultant physician

ROGER WILLIAMS, MD, FRCP, director and consultant physician
}

Hepatitis Research Unit, London School of Hygiene and Tropical Medicine, London WC1

A J ZUCKERMAN, MD, DSC, professor of microbiology discussion about the risk of dental staff transmitting HBsAg to their patients. Most of the reports in the UK and USA have based their conclusions on studies of general dental practitioners. Members of staff of a dental school are perhaps more at risk, particularly at centres such as this, where the medical and dental school are on the same site and where medical inpatients are often referred for dental treatment. There are also specialised liver and renal dialysis units and two drug dependency centres in the immediate vicinity. Furthermore, the local population includes many immigrants, many of whom are from areas where $\mathrm{HBsAg}$ carriage is highly prevalent.

We report here the results of a detailed survey of the clinical dental staff.

\section{Methods}

Of the 80 dental surgeons working at the dental school, 61 with direct clinical responsibility agreed to take part in this study, which was carried out in April to September 1975. Their ages ranged from 24 to 60 years (mean 36$) ; 52$ were men and nine were women. Only 12 specialised in oral and maxillofacial surgery.

One of us (GG) interviewed all the dental surgeons. A comprehensive questionnaire was completed in their presence, which included details of type and length of dental practice, including time spent abroad, whether there was a history of blood transfusions or contact with jaundiced patients, drug addicts, or patients with chronic liver or renal disease. If there was a history of jaundice they were asked whether the diagnosis had been confirmed by blood examination and whether the hepatitis was type A or B.

A blood sample was taken at the interview and examined for HBsAg using radioimmunoassay. ${ }^{3}$ This was based on a solid-phase technique ${ }^{4}$ using polypropylene tubes coated with hepatitis B antibody (Abbott). The guinea-pig antibody possessed anti-a, anti-d, and anti-y specificities. The specificity of all the results was checked by repeating the assay after neutralisation with antibody to $\mathrm{HBsAg}$ (HBsAb). $\mathrm{HBsAb}$ was detected using a solid-phase radioimmunoassay system similar to that used for detecting the antigen. ${ }^{5}{ }^{125}$ I-labelled HBsAg of human origin was mixed with the serum to be tested and then added in a one-step procedure to polypropylene tubes previously coated with $\mathrm{HBsAg}$. After incubation and washing the radioactivity in each tube was measured in a gamma-scintillation counter.

\section{Results}

Analysis of the questionnaire showed that 27 of the 61 dental surgeons had knowingly treated $\mathrm{HBsAg}$-positive patients, some of them many times, but they had always taken appropriate precautions, such as wearing a mask and gloves. Six dental surgeons $(10 \%)$, five of whom had been engaged in dental practice for long periods (19 to 37 years), 
had had acute hepatitis during their career. Only four of these were thought to have had type B hepatitis, however; in one of the others the hepatitis had been associated with glandular fever and in another with a possible reaction to antibiotic treatment. One had had two episodes of hepatitis. Only one of the dental surgeons had had hepatitis while employed at King's (1974). Blood samples taken at the time of his acute illness were positive for hepatitis B antigen on immunoelectrophoresis but became negative when he recovered.

Four dental surgeons had received blood transfusions, but none had developed hepatitis. About a third of the dental surgeons in the survey had lived abroad during their career for six months to 45 years, but none had had clinical hepatitis during those times.

\section{SEROLOGICAL STUDIES}

Serum from only one dentist was positive for HBsAg during the survey. He had no symptoms and the antigenaemia was transient, all tests, including radioimmunoassay for $\mathrm{HBsAg}$ and $\mathrm{HBsAb}$ being negative four months later. Seven months earlier he had been in contact at another hospital with a patient who had HBsAg-positive chronic liver disease.

Four dental surgeons had antibodies to $\mathrm{HBsAg}$, one of them being the dentist who had had a clinical attack of acute viral hepatitis B while working at King's in June 1974. He said that he had removed a wisdom tooth in November 1973 from a patient under local anaesthesia who was a drug addict and had HBsAg-positive chronic liver disease. At the time the patient denied any history of drug addiction and did not admit to a previous episode of hepatitis. Consequently no precautions were taken during the operation. Subsequently this patient developed a submasseteric abscess and had to be admitted for incisional drainage. This time, however, she admitted to her addiction to obtain further narcotic injections. Accordingly, the drainage procedure was performed with full sterile theatre procedure. Neither of the other two surgeons concerned in this procedure developed clinical hepatitis and their sera, obtained during the survey, about 18 months later, were negative for $\mathrm{HBsAb}$ as well as for $\mathrm{HBsAg}$.

The other three staff members with detectable HBsAb had lived abroad for varying periods (Africa and the Far east 30 years, Persia 45 years, and New Zealand 11 years). Two of them had also often treated $\mathrm{HBsAg}$-positive patients for conservation, both at King's and elsewhere. Further analysis of the results in relation to the main occupation of the dentists tested did not show any particular association between this and the history or occurrence of clinical hepatitis, HBsAb, or HBsAg.

\section{Discussion}

Dental treatment entails the use of sharp instruments in a field contaminated with saliva and, not infrequently, with blood. Furthermore, the use of ultrasonic rotary instruments and air and water sprays creates a potentially infectious aerosol. Dental surgeons who wear glasses and work with ultrasonic and rotary instruments know the amount of dirt and droplets of saliva, blood, and water that the aerosol deposits on their glasses. These could contaminate unprotected abrasions and cuts on fingers, hands, and faces or any exposed skin surface. Almost all the dental surgeons in this survey stated that accidental puncture of the skin of the hands occurred at least once a month or so.

As little as $0.004 \mathrm{ml}$ of $\mathrm{HBsAg}$-positive blood injected parenterally may transmit hepatitis $\mathrm{B} .^{6}$ Although there is some doubt about the quantities involved, $\mathrm{HBsAg}$ has also been detected in saliva, ${ }^{78}$ and this may constitute a particular hazard for dental and oral surgeons. Nevertheless, the relative importance of these sources of infection in the transmission of HBsAg-positive hepatitis is unknown.

Another factor that may be important in determining the chances of acquiring $\mathrm{HBsAg}$ from antigen-positive patients is whether they are true carriers or have underlying chronic liver disease. The latter are possibly more likely to transmit infection than true carriers with no liver damage. ${ }^{9}$ It is of interest that the one dentist found to be HBsAg positive and the other who was known to have contracted hepatitis $B$ were both in contact with patients with $\mathrm{HBsAg}$-positive chronic liver disease.

Although hospital dental surgeons may be particularly vulnerable because patients with liver disease may be referred for treatment, they can take appropriate precautions provided the HBsAg status of their patients is known. Indeed the infection rate in this study, as judged by the prevalence of $\mathrm{HBsAb}$, was small. It did not differ significantly from the $7 \%$ incidence we found in 43 factory workers. ${ }^{10}$ In considering the measures dental surgeons can take to protect themselves and their patients, clearly testing all patients for $\mathrm{HBsAg}$ before dental treatment is impractical, not only economically but also because of the inevitable delay to patients needing urgent treatment. A practical alternative is to take a good medical history, emphasising hepatitis, blood transfusion, or drug abuse, and to refer suspected cases for blood testing. Essential precautions when treating HBsAg-positive patients include the use of a mask and gloves. If the skin is accidentally punctured and contaminated with potential HBsAg-positive material an injection of hepatitis B immunoglobulin should be given, as it seems clear from several controlled studies that this will probably give adequate protection. ${ }^{10}$

From the patient's point of view there are two problems: firstly, the prevention of cross-infection from one patient to another by the dental instrument; and, secondly, the potential hazard of an HBsAg-positive dental surgeon to his patients. With regard to the first, there is likely to be less risk of contamination to others if antigen-positive patients are treated at the end of the day. As many disposable instruments should be used as possible and it is conventional practice to soak the remainder in $1 / 10$ sodium hypochlorite or $2 \%$ gluteraldehyde. Any spilt blood should be washed with 1/100 hypochlorite solution.

Secondly, the risk of transmitting HBsAg-positive hepatitis from an asymptomatic carrier dental surgeon to his professional contacts is less easily defined. Both the published reports of dental workers transmitting hepatitis to their patients, one incriminating a nurse and the other a dentist, are somewhat inconclusive. Indeed, Williams et $a l_{,}{ }^{13}$ who prospectively followed 237 patients who had been treated by two dentists during the incubation period of acute $\mathrm{HBsAg}$-positive hepatitis (household members of the exposed patients served as controls), found that none of the patients contracted overt hepatitis or HBsAg. In another study Alter et $a l^{14}$ followed 228 contacts of five HBsAg-positive health care workers, including two physicians and a nurse who were healthy carriers and a physician and a food handler who worked during the prodrome of acute HBsAg-positive hepatitis. None of the contacts, followed for six to nine months, developed HBsAg-positive hepatitis.

From the viewpoint of their own health, however, undoubtedly dental surgeons who are found to be $\mathrm{HBsAg}$-positive ought to be investigated to determine whether they are entirely healthy carriers or whether there is some form of underlying liver disease that may need treating. But provided that they take the additional precautions already outlined, we believe that the current evidence does not warrant any restriction of their professional activities.

\section{References}

${ }_{1}$ Mosley, J W, et al, New England Fournal of Medicine, 1975, 292, 729.

2 Glenwright, H D, et al, British Dental fournal, 1974, 136, 409.

3 World Health Organisation, Viral Hepatitis, Technical Report Series No 512. Geneva, WHO, 1973.

4 Catt, K, and Treager, G W, Science, 1967, 158, 1570.

5 Reed, W D, et al, Lancet, 1973, 2, 690.

${ }^{6}$ Beeson, P B, et al, in Cecil-Loeb Textbook of Medicine. London, Saunders, 1971.

7 Ward, R, et al, Lancet, 1973, 2, 726.

${ }^{8}$ Heathcote, J, et al, Lancet, 1974, 1, 71 .

${ }^{9}$ Heathcote, J, et al, Lancet, 1974, 2, 370.

10 British Medical fournal, 1976, 1, 241.

${ }^{11}$ Garibaldi, R A, et al, fournal of the American Medical Association, 1972, 219, 1577.

12 Levin, M L, et al, fournal of the American Medical Association, 1974 228, 1139

13 Williams, S V, et al, fournal of the American Medical Association, 1975, 232, 1231

${ }^{14}$ Alter, H J, et al, New England fournal of Medicine, 1975, 292, 455. 